\title{
ESTUDOS CULTURAIS, ENSINO E DIVERSIDADES \\ SURDOS UNIVERSITÁRIOS: REFLEXÃO NA UNIVERSIDADE
}

\author{
Geraldo Venceslau de Lima Júnior \\ geraldovenceslau@gmail.com \\ Karine Martins Cunha Venceslau \\ karine.mcunha@gmail.com \\ Natalia Diniz Silva \\ nataliadiniz01@gmail.com
}

\begin{abstract}
RESUMO
A importância deste artigo é debater as condições oferecidas aos alunos surdos que frequentam o ensino superior, bem como cooperar experiências acadêmicas, para que tenha maior qualidade na realidade atual, visto que as modificações propostas pela política oficial para a educação de surdos em todos os níveis não estão ainda efetivamente inseridas nem as instituições educacionais preparadas para responder às necessidades desses alunos. O objetivo da pesquisa é argumentar e debater sobre a inclusão e a realidade dos níveis e modalidades da educação escolar. Acolher alunos surdos na universidade é um serviço emergencial e prioritário, porém, é um fato real, onde esses sujeitos ainda encaram obstáculos educacionais. Nesse assunto, apresenta-se a pesquisa, cujo tema refere-se à "Surdos Universitários: reflexão na Universidade"
\end{abstract}

\section{INTRODUÇÃO}

O número de alunos surdos que cursam o Ensino Superior está expandindo-se cada vez mais, no Brasil. Segundo dados do Ministério da Educação, em 2003, somente surdos cursavam a universidade. Em 2005, aumentou-se para 2.428, entre instituições públicas e privadas (Brasil, 2006).

O grande comparecimento de alunos surdos em contextos universitários é contemporâneo, e passa de distintas causas, que podem ser supramencionadas, como o reconhecimento, quando em 1990, do status de língua oral para a língua de sinais; criação de propostas de educação bilíngue de qualidade para surdos; e o trajeto histórico onde as políticas públicas de inclusão focam ao acesso e a participação ativa de pessoas com deficiência em diversas situações sociais. 
De acordo com o ministro, os dados do censo revelam que a educação superior no Brasil está mais acessível. Dos 5.954.021 estudantes matriculados em 28.671 cursos de graduação presencial e a distância, 2.065.082 são ingressantes e 839.397 estão em instituições federais de ensino superior.

$\mathrm{Na}$ graduação presencial das instituições públicas, 36.294 ingressos ocorreram por meio de reserva de vagas, principalmente para alunos oriundos de escolas públicas. Além disso, em 2009 foram contadas 20.019 matrículas de estudantes com algum tipo de deficiência (30\% com baixa visão, $22 \%$ com deficiência auditiva e 21\%, física). (Inep.gov.br; acessado em 23/04/2015)

\section{OBJETIVO:}

O objetivo da pesquisa é argumentar e debater sobre a inclusão e a realidade dos níveis e modalidades da educação escolar. Acolher alunos surdos na universidade é um serviço emergencial e prioritário, porém, é um fato real, onde esses sujeitos ainda encaram obstáculos educacionais.

\section{1 - Visão dos alunos Surdos no contexto universitário}

A situação universitária é desafiadora para qualquer cidadão. Adaptações na vida acadêmica, um dos desafiadores dos alunos universitários, obrigações que a universidade impõe transportam muitas vezes ao fracasso e ao abandono. Para obter assimilações com novas informações e novos conhecimentos, é necessário utilizar a contornação das falhas causadas dentro do trajeto escolar em que vivenciou anteriormente, como deficiências de linguagem, inadequação das condições de estudo, falta de habilidades lógicas, problemas de compreensão em leitura e dificuldade de produção de textos conforme Sampaio, Santos, 2002. 
O ambiente, professores, colegas são pontos triplos relevantes para que os desempenhos das atividades acadêmicas tornem de maneira estável e linear, com o fim de melhorar as chances de êxito, menciona Diniz, Almeida, 2005

Os jovens surdos, como quaisquer outros, terão de fazer frente a expectativas, normas e modos de funcionamento diferentes daqueles de sua experiência escolar anterior. A adaptação a essa nova realidade dependerá de suas características pessoais, habilidades, de sua história e da forma como encara esse período de desenvolvimento próprio da faixa etária do jovem adulto, marcado pela construção da identidade, da autonomia, de ideais e de relações interpessoais (FERREIRA, ALMEIDA, SOARES, 2001).

Foster, Long e Snell (1999), fez uma pesquisa a respeito da vivência de estudantes surdos do ensino superior em contextos de inclusão, onde corrobora que a comunicação desses em sala de aula e o envolvimento com a aprendizagem são análogas a de seus colegas ouvintes Outro ponto relevante são os professores, que não tem a base de conhecimento de como lidar com os alunos surdos, bem como as adaptações metodológicas, que não são feitas, causando falhas aos alunos surdos.

Segundo Goffredo (2004), para consentir às necessidades educacionais especiais dos jovens surdos, é preciso primeiramente, assegurar seu ingresso na universidade por meio do vestibular. Mas isso não garante que a inclusão se concretize. Vencida a barreira do ingresso, o próximo passo é a permanência no curso, que depende muito da mediação do intérprete e do conhecimento dentro da universidade de como lidar com os estudantes surdos.

No Brasil, a legislação que trata da inclusão de surdos em instituições de ensino regulares (Brasil, 2003) estabelece que se deve oferecer, sempre que necessário, um intérprete de Língua Brasileira de Sinais/Língua Portuguesa, e recomenda flexibilidade na correção da escrita na provas, de modo a valorizar o conteúdo semântico.

Segundo Martins:

...os intérpretes vêm procurando construir, a partir de sua inscrição na educação, entre e com os surdos, seu lugar na triangulação "professor 
ouvinte, ILS, inteprete de língua de sinais] e aluno surdo" - um espaço no entre que a própria tradução instaura. (2007, p.178)

Martins (2006), afirma que o papel do intérprete da língua de sinais, é notar as dificuldades do aluno surdo e desviar outros modos e métodos de trabalhar com eles. É um ciclo transitório entre o aluno, o professor e conhecimento, com a finalidade de apoiar a superação linguística na interação comunicativa. Por isso, acrescenta a autora, o desempenho do intérprete requer-se de maneira profunda conhecer a base teórica em diferentes áreas de estudo, familiaridade com a linguagem utilizada em cada situação e experiência educacional.

Foster, Long e Snell (1999) levantam outros problemas enfrentados pelos estudantes surdos: o feedback das informações complexo (tempo entre o que é falado e a tradução); o contato visual - caso o aluno observa o interprete interpretando o aluno surdo desconectara a visão do professor, ou caso o aluno queira ler algum material, as informações contidas já serão perdidas por não utilizar o visual ou leitura labial. É uma falha para os alunos surdos.

Os assuntos complexos que envolvem o desempenho acadêmico de estudantes surdos ainda precisam ser trabalhados de maneira profunda. Conforme Lang (2002), mesmo em países tradicionais com a inclusão de surdos em instituições de ensino superior - como os Estados Unidos, onde em 1999 eles eram mais de 25 mil - há maior compreensão sobre as barreiras e dificuldades do que sobre as soluções. O que existe de caráter prático são diretrizes gerais, como o respeito à diferença linguística e a oferta de contribuições metodológicas específicas, como materiais especiais, novas tecnologias de ensino e serviços de apoio diferenciados, confirma Martins, 2006.

\section{METODOLOGIA}

$\mathrm{Na}$ pesquisa bibliográfica foram examinadas diversas literaturas relativas ao assunto em estudo, artigos publicados na internet e que possibilitaram que este trabalho tomasse forma para ser baseado.

Conforme Marconi e Lakatos (1992), a pesquisa bibliográfica é o levantamento de toda a bibliografia já publicada, em forma de livros, revistas, publicações avulsas e imprensa 
escrita. O escopo é fazer com que o pesquisador entre em contato direto com todo o material escrito sobre um determinado assunto, auxiliando o cientista na análise de suas pesquisas ou na manipulação de suas informações.

Conforme Marconi e Lakatos (1992), a pesquisa de campo é uma forma de levantamento de dados no próprio local onde ocorrem os fenômenos, através da observação direta, entrevistas e medidas de opinião.

D acordo com Marconi e Lakatos (1985), a entrevista é um encontro entre dois seres, a fim de que uma deles consiga dados a respeito de determinado assunto, mediante uma conversação de natureza profissional.

\section{CONCLUSAO}

Vários ares devem ser examinados ao se analisar o caso dos surdos que ingressam no ensino superior. No mínimo, é conciso analisar sua trajetória escolar e o contexto institucional em que ele busca se inserir.

Realmente a universidade é um contexto novo e desconhecido para os jovens surdos, com requisições superiores àquelas a que estavam habituados na escola especial. Seu funcionamento é administrado por regras, princípios e características do mundo ouvinte, onde a comunicação oral-auditiva é desempenhada no papel fundamental na organização dos espaços de ensino-aprendizagem e de socialização.

Geralmente muitas das vezes os colegas e professores são ouvintes, estes desconhecem as especificidades relativas à surdez, que acaba compartilhando propostas e ideias senso comum, ignora a língua de sinais e tem dificuldade de se relacionar com o que é, em um grau mais significativo, diferente.

\section{REFERÊNCIA BIBLIOGRAFIA}


BRASIL. Ensino de língua portuguesa para surdos: caminhos para a prática pedagógica. Vol I e II. Brasília: MEC/SEESP, 2006 Portaria n.3.284, de 7 de novembro 2003. Brasília, 2003.

DINIZ, A. M.; ALMEIDA, L. S. Escala de integração social no ensino superior (Eises): metodologia de construção e validação. Análise Psicológica, v.4, n.23, p.461-476, out. 2005.

FERREIRA, J. A.; ALMEIDA, L. S.; SOARES, A. P. C. Adaptação acadêmica em estudante do $1^{\circ}$ ano: diferenças de gênero, situação de estudante e curso. PsicoUSF, Itatiba, v.6, n.1, p.1-10, jan. 2001.

FOSTER, S.; LONG, G.; SNELL, K. Inclusive instruction and learning for deaf students in postsecondary education. Journal of Deaf Studies and Deaf Education, Oxford, v.4, n.3, p.225-235, Summer, 1999.

GOFFREDO, V. L. F. S. A Inclusão da pessoa surda no ensino superior. Fórum, Rio de Janeiro, v.10, p.16-22, dez. 2004.

MARTINS, V. R. O. Implicações e conquistas da atuação do intérprete de língua de sinais no ensino superior. Educação Temática Digital, Campinas, v.7, n.2, p.157-166, jun. 2006.

Intérprete de língua de sinais, legislação e educação: o que temos, ainda, a "escutar" sobre isso? Revista Educação Temática Digital, Campinas, v.8 (esp.), p.117191,jun. 2007.

SAMPAIO, I. S.; SANTOS, A. A. Leitura e redação entre universitários: avaliação de um programa de intervenção. Psicologia em Estudo, Maringá, v.7, n.1, p.31-38, jan. 2002.

QUADROS, Ronice Muller de. Educação de Surdos: a aquisição da linguagem. Porto Alegre, Artes Médicas, 1997 da parte referenciada. 